\title{
Investigation of Hydrochar Derived from Male Oil Palm Flower: Characteristics and Application for Dye Removal
}

\author{
Ahmad Said $^{1}$, Surajit Tekasakul ${ }^{1}$, Khamphe Phoungthong ${ }^{2,3 *}$ \\ ${ }^{1}$ Department of Chemistry, Faculty of Science, Prince of Songkla University, Songkhla, Thailand \\ ${ }^{2}$ Environmental Assessment and Technology for Hazardous Waste Management Research Center, \\ Faculty of Environmental Management, Prince of Songkla University, Songkhla, Thailand \\ ${ }^{3}$ Center of Excellence on Hazardous Substance Management (HSM), Bangkok, Thailand
}

Received: 30 May 2018

Accepted: 24 January 2019

\begin{abstract}
Male oil palm flower (MOPF) is an abundant and otherwise useless waste from oil palm cultivation. This work aimed to transform MOPF to hydrochar and use it as an adsorbent for the removal of methylene blue (MB) dye in water systems, thus dealing with two existing environmental issues simultaneously. The raw biomass was converted to hydrochar at $180^{\circ} \mathrm{C}$ for $8 \mathrm{~h}$ in an air atmosphere. Characterization of the hydrochar using FTIR resulted in a change of functional groups after hydrothermal carbonization (HTC) as well as after adsorption, which might involve in MB adsorption. The small increase of pores in hydrochar detected in the BET isotherm analysis might also facilitate MB adsorption. SEM images confirmed the existence of pores on the hydrochar in comparison with the raw biomass. The equilibrium MB adsorption followed a pseudo second-order and a Langmuir isotherm model with the maximum adsorption capacity of $42.92 \mathrm{mg} \cdot \mathrm{g}^{-1}$ at $30^{\circ} \mathrm{C}$. These findings suggest that MOPF could be a low-cost valueadded material and an alternative eco-friendlyhydrochar-based adsorbent for MB removal from aqueous solution.
\end{abstract}

Keywords: agricultural waste, male oil palm flower, hydrochar, adsorbent, dye

\section{Introduction}

Southeast Asia is the region most heavily planted with oil palm tree in the world. As the third-ranking country producing palm oil, a large quantity of oil palm tree waste is generated in Thailand. Thailand's palm oil production achieves roughly 11-13 million tons or a

$\overline{\text { *e-mail: khamphe.p@psu.ac.th }}$ matter of $1.2 \%$ of world production [1]. These biomass wastes may come from plantations (oil palm trunks and fronds) or palm oil mills (empty fruit bunches, mesocarp fiber, and palm kernel shells) [2]. Wastes such as trunks of the plant, fronds, and both male and female flower are direct agricultural wastes along pruning and harvesting seasons. Among the parts of the oil palm tree, male flowers are not currently used productively once they have matured. In the life-cycle of the palm tree, the male flower, which grows separately in a spike, fertilizes the female flowers. The oil palm is a monoecious plant with 
a productive life of around 25 years. During that time both male and female flowers continually develop and the male flowers pollinate the female flowers,which then change into fruit clusters while the male flowers, mature and no longer bear pollen. The male inflorescence is produced in higher numbers than female flowersand there are actually around five times as many male as female flowers[3]. Generally, the mature male flowersare either left on the tree or aborted and utilized for compost in the plantation. However, the decomposition of this compost takes a long time and its presence in large quantities in the vicinity of the palm trees causes the plantations to become untidy. Increasing palm tree cultivation leads to a large amount of this waste in every country that produces palm oil, including Thailand, and represents an environmental issue.

Many researchers have investigated converting agricultural wastes, especially those from oil palm residues, into value-added materials. Biomass wastes from oil palm plantations can be used to efficientlytreat pollutants as well as for the production of energy due to their widespread availability and low-cost. They can be used as unmodified biomass-based adsorbents, which, because of their active surface functional groups,are effective for the selective sorption of heavy metals [4]. They can also be used to produce modified biomass products such as biochar with or without activation [5-6], which can be used for dye removal [7-8].

Biochar can be produced by thermochemical processes such as hydrothermal carbonization (HTC), pyrolysis or combustion. The products of these conversions have different properties and applications. HTC is one thermal technique for converting biomass into a lignite-like solid product:hydrochar. HTC requires feed water as the reaction medium in a closed system, which would result in high pressure inside due to heating the water at the subcritical or supercritical water points. The HTC reaction is carried out at a low temperature and no drying process or pre-treatment is necessary as the reaction can be conducted using wet materials and still result in a high conversion percentage. Since the process is inexpensive and involves low energy consumption, hydrochar, as the solid product of HTC, has been widely used for many applications, including energy production, soil amendment and also the removal of pollutants. Previous studies have also applied hydrochar for the adsorption of metals [9-10], dyes [11], and pharmaceuticals [12]. In the HTC treatment, those three compounds of hemicellulose, cellulose, and lignin can be degraded at a lower temperature, likely at $180^{\circ} \mathrm{C}$ and $160 \mathrm{oC}$ or around subcritical water for cellulose and hemicellulose decomposition serially, and lignin can occur at near or about supercritical water [13]. It has opened the mind to choose HTC as a lower-cost technique than pyrolysis.

Methylene blue (MB) is a common dye that is widely used in the textile, pulp, paper, food and plastic industries. Due to its toxicity and large amounts, this dye needs to be treated after use and before disposal into the natural environment in order to prevent pollution. Prolonged exposure to MB leads to chronic complaints in humans such as increased heart rate, shock, vomiting, jaundice, Heinzh-Erlich body formation, cyanosis, quadriplegia, and tissue necrosis [14]. Various techniques have been applied to remove MB, including membrane separation, photocatalytic degradation, electrochemical treatment, and adsorption. Among those methods, adsorption is notable as beinga simple and efficient technique for the removal of pollutants with a clear procedure to be followed.

Based on the above, the aims of this study were two-fold. The main goal was converting male oil palm flowers (MOPF) into a value-added material (hydrochar) and investigating its physicochemical properties by $\mathrm{pH}_{\mathrm{pzc}}$ measurement, FT-IR spectroscopy, elemental analysis, BET isotherm analysis, and SEM, and comparing those properties with the raw material used. Most researchers work on hydrochar with either chemical activation or physical activation in order to improve the hydrochar's properties. However, adding the activating agents may increase the process cost and new contaminant from the chemicals added. In order to obtain fabulous behavior on hydrochar, we need to play with the operation temperature and time. Increasing the operating temperature will increase carbon content on hydrochar, while it may decrease the hydrogen and oxygen contents [15]. The surface area of hydrochar enlarges also with upgrading the temperature [16]. Secondly, the hydrochar produced was applied in an aquatic system contaminated with MB dye and the removal of the dye was conducted using the adsorption technique. In order to understand the mechanism of MB adsorption, kinetic and isotherm models were also constructed.

\section{Experimental}

\section{Materials and Reagents}

Mature MOPF, which had either been aborted or remained on the oil palm tree (Elaeisguineensis), was collected during 2016 and 2017 from HatYai District, Songkhla Province, Thailand.MB of technical reagent grade was purchased from Ajax Finechem. HCland $\mathrm{NaCl}$ used was of analytical reagent grade.

\section{Hydrocharpreparation}

The MOPF was first washed with deionized (DI) water several times to remove dust and other soluble impurities and then dried in an oven overnight. The raw material was ground into smaller particles in a grinder and refined with a sieving device into a range of $0.841-0.595 \mathrm{~mm}$, then stored in plastic bags at room temperature. The HTC process was conducted by adding the feedstock into a $400 \mathrm{~mL}$ Teflon-lined autoclave reactor and heating it to $180^{\circ} \mathrm{C}$. The thermal conversion was conducted for $8 \mathrm{~h}$ with a biomass-to-water ratio of 
$10 \mathrm{wt} \%$. After the reaction was completed, the reactor was allowed to cool to room temperature. The hydrochar obtained was filtered using a vacuum technique. The solid was then boiled with DI water to release the water-soluble volatile compounds and the residue was then filtered and washed several times with DI water. Afterward, the solid, hydrochar, was dried in an oven for $24 \mathrm{~h}$ to ensure that it was completely dry. Hydrochar was produced three times under the same conditions producing the same characteristics in order to establish the average yield percentage. The hydrochars were then mixed and stored in a sealed plastic bag for future use.

\section{Characterization}

The properties of the hydrochar obtained were then examined. First, the $\mathrm{pH}_{\mathrm{pzc}}$ (the point of zero charge, i.e., the $\mathrm{pH}$ at which the sample has zero charge) was determined following the previous method [17]: about $25 \mathrm{~mL}$ of $\mathrm{NaCl}$ aqueous solution with $\mathrm{pH}$ ranges of 2-10 was added into $0.10 \mathrm{~g}$ of sample then the mixtures were swirled for $24 \mathrm{~h}$. The $\mathrm{pH}$ of the solutions was measured using a DELTA $320 \mathrm{pH}$ meter, plotting between initial $\mathrm{pH}$ against final $\mathrm{pH}$ resulted in $\mathrm{pH}_{\mathrm{pzc}}$ at the point that the initial $\mathrm{pH}$ was equal the final $\mathrm{pH}$. Elemental analysis was conducted using a Flash 2000 elemental analyzer to detect the element contents. The specific surface area was measured by Nitrogen sorption isotherm analysis with an ASAP 2460 surface area and porosity analyzer (Micrometrics, USA) and was calculated using the BET (Brunauer-Emmett-Teller) method. The morphology and textural structure were examined using a Quanta 01 Scanning Electron Microscope (SEM). The surface functional groups were observed using a Perkin Elmer Spectrum BX FTIR spectroscope. The IR spectra were recorded in the range of $4000-400 \mathrm{~cm}^{-1}$ at $4 \mathrm{~cm}^{-1}$ resolution using the Potassium Bromide $(\mathrm{KBr})$ pellet method. The same tests were performed on both the hydrochar and the MOPF raw material in order to obtain comparative results.

\section{Batch Sorption Experiment}

The Hydrochar's MB sorption ability was examined in a batch sorption experimental. To study the equilibrium time of MB adsorption onto the hydrochar, a sample of $0.20 \mathrm{~g}$ was placed into a- $250 \mathrm{~mL}$ Erlenmeyer flask containing $200 \mathrm{~mL}$ of $300 \mathrm{mg} \cdot \mathrm{L}^{-1}$ of $\mathrm{MB}$ solution for $48 \mathrm{~h}$ at room temperature using a mechanical shaker at $400 \mathrm{rpm}$. This data obtained were used for kinetic study. The sorbent dosage effect was observed using adsorbent doses in the range of 0.005-0.2 g.
The adsorption isotherm experiments were conducted at $30^{\circ} \mathrm{C}$ using $0.2 \mathrm{~g}$ of hydrochar in $50 \mathrm{~mL}$ of $\mathrm{MB}$ solution with an initial concentration range of 25 to $300 \mathrm{mg} \cdot \mathrm{L}^{-1}$. The final concentrations were measured using a UV-visible spectrophotometer (SHIMADZU, UV-2600, Japan) at a maximum wavelength of $664 \mathrm{~nm}$. The MB solutions were used at their natural $\mathrm{pH}$, which were in the range 4.71-5.21. The adsorption efficiency $(\% \mathrm{E})$ and adsorption capacity $\left(\mathrm{Q}_{\mathrm{e}}\right)$ were calculated using the following equations (1) and (2):

$$
\begin{gathered}
\% \mathrm{E}=\left(\left(\mathrm{C}_{0}-\mathrm{C}\right) / \mathrm{C}_{0}\right) \times 100 \% \\
\mathrm{Q}_{\mathrm{e}}=\left(\left(\mathrm{C}_{0}-\mathrm{C}\right) / \mathrm{m}\right) \times \mathrm{V}
\end{gathered}
$$

...where $\mathrm{C}_{0}$ and $\mathrm{C}$ are the initial and final concentrations of the MB solutions, respectively, in $\mathrm{mg} \cdot \mathrm{L}^{-1}, \mathrm{~V}$ is the dye solution volume in $\mathrm{L}$, and $\mathrm{m}$ is the mass of adsorbent used in each experiment in $\mathrm{g}$.

\section{Results and Discussion}

\section{Characterization of the Hydrochar}

The prepared hydrochar with a yield of $58.02 \pm 0.74 \%$ was characterized using an elemental analyzer, a BET sorptometer, SEM, and FTIR. The textural and elemental compositions of the hydrocharare shown in Table 1 . The $\mathrm{pHpzc}$ is the $\mathrm{pH}$ corresponding to a net charge of zero on the adsorbent's surface [17] and indicates a possible mechanism for the adsorption interaction between the adsorbent and the adsorbate. The $\mathrm{pH}_{\mathrm{pzc}}$ was found to be 5.8 for hydrochar prepared from MOPF. To produce appropriate adsorption of $\mathrm{MB}$ (a cationic dye), the $\mathrm{pH}$ of the MB solution should be higher than the $\mathrm{pH}_{\mathrm{pzc}}$ of the adsorbent $\left(\mathrm{pH}>\mathrm{pH}_{\mathrm{pzc}}\right)$, because the adsorbent's surface will thus be negatively charged [18]. However, the purpose of this work was to investigate the adsorption efficiency under the condition of less chemicals usage, therefore the $\mathrm{pH}$ of $\mathrm{MB}$ solutions was not adjusted to be greater than $\mathrm{pH}_{\mathrm{pzc}}$. The $\mathrm{pH}$ of the hydrochar was more acidic than that of the raw material (Table 1). This was similar to previous studies that the HTC process produces inorganic acids from biomass due to organic catalysts produced during the decomposition process of cellulose, resulting in a relatively acidic $\mathrm{pH}[15,19]$. Tran et al. [20] similarly found that the $\mathrm{pH}_{\mathrm{pzc}}$ of hydrochar tended to be acidic, with acidic groups exhibited by the hydrochar dominating.

The elemental composition of both the hydrocharand the MOPF was determined and are shown in Table 1 in

Table 1. Basic properties of hydrochar and MOPF.

\begin{tabular}{|c|c|c|c|c|c|c|c|}
\hline Sample & Yield (\%) & $\mathrm{pH}_{\mathrm{pzc}}$ & $\mathrm{C}(\%)$ & $\mathrm{H}(\%)$ & $\mathrm{N}(\%)$ & $\mathrm{O}(\%)$ & $\mathrm{S}_{\mathrm{BET}}\left(\mathrm{m}^{2} \cdot \mathbf{g}^{-1}\right)$ \\
\hline MOPF & - & 7.1 & 42.76 & 5.07 & 1.56 & 37.43 & 1.28 \\
\hline Hydrochar & 58.89 & 5.8 & 49.94 & 5.08 & 1.59 & 32.32 & 5.30 \\
\hline
\end{tabular}


terms of theircarbon, hydrogen, nitrogen, and oxygen contents. The carbon content of the hydrochar was higher than that of the raw MOPF due to the formation of aromatic carbon, which was consistent with oxygen depletion due to dehydration and decarboxylation processes occurring during $\mathrm{HTC}$, where the $\mathrm{H}$ and $\mathrm{O}$ were removed from the solid biomass in the form of $\mathrm{H}_{2} \mathrm{O}$ and $\mathrm{CO}_{2}[10,15,21]$. There was no difference in $\mathrm{N}$ content between the hydrochar and the biomass, which might be because the nitrogen did not dissolve in the processing liquid [22]. This result was comparable to the previous study of Chen et al. [23], who tested hydrochar derived from sweet potato waste and that of Nakason et al. [24], who examined cassava rhizomebased hydrochar. They noted that the carbon content of the hydrochar increased, while the $\mathrm{H}$ and $\mathrm{O}$ contents declined. The results were similar in this work due to the decomposition and cracking of the biomass after $\mathrm{HTC}$, which resulted in the production of $\mathrm{H}_{2}, \mathrm{CH}_{4}, \mathrm{CO}$ and $\mathrm{CO}_{2}$ gases [25].

The surface area of the hydrochar was investigated using nitrogen adsorption-desorption isotherm analysis. A higher surface area $\left(5.30 \mathrm{~m}^{2} \cdot \mathrm{g}^{-1}\right)$ was observed forthe hydrochar than for the MOPF $\left(1.28 \mathrm{~m}^{2} \cdot \mathrm{g}^{-1}\right)$ because the carbonization process removed some organic compounds and opened the material's pores. The extent of the surface area revealed that the HTC process leads to a low porosity-based material. However the value obtained was slightly higher than that for hydrochar prepared from canola stalk by $\mathrm{HTC}$ at $207^{\circ} \mathrm{C}$ for $82 \mathrm{~min}$ $\left(2.69 \mathrm{~m}^{2} \cdot \mathrm{g}^{-1}\right)$ [26]. Tran et al. [20] prepared hydrochar from golden shower at $190^{\circ} \mathrm{C}$ for $24 \mathrm{~h}$, which produced a surface area $\left(24.80 \mathrm{~m}^{2} \cdot \mathrm{g}^{-1}\right)$ almost three times higher than the precursor $\left(8.14 \mathrm{~m}^{2} \cdot \mathrm{g}^{-1}\right)$, which was due to the weak decomposition of cellulose and lignin during the HTC process. However, an increase of surface area confirmed that the $\mathrm{HTC}$ at $180^{\circ} \mathrm{C}$ for $8 \mathrm{~h}$ had been successful. In addition, an increase of surface area in the hydrochar may indicate an increase in the binding sites for appropriate interaction with adsorbate substances [27]. Overall, Zhu et al. [28] suggested that the conditions of the HTC process strongly affect the porosity of hydrochar-based porous carbon.

SEM images at 5000X magnification were used to investigate the textural and morphological changes after hydrothermal treatment and these are shown in Fig. 1. The MOPF showed a dense morphology without any porous structures. On the other hand, the hydrocharprepared presented a slightly modified surface possibly due to hydrothermal carbonization driven openand-shut porosity development through establishing cavities with different sizes and areas that affect the distribution of surface sites on the hydrochar [10]. The elementary porosity can be linked to the increase in the surface area of the hydrochar compared to the biomass [29]. This result represents evidence of successful HTC due to hydrolysis and carbonization reactions that broke down the organic compounds during the hydrothermal conversion of the MOPF [25]. A previous study
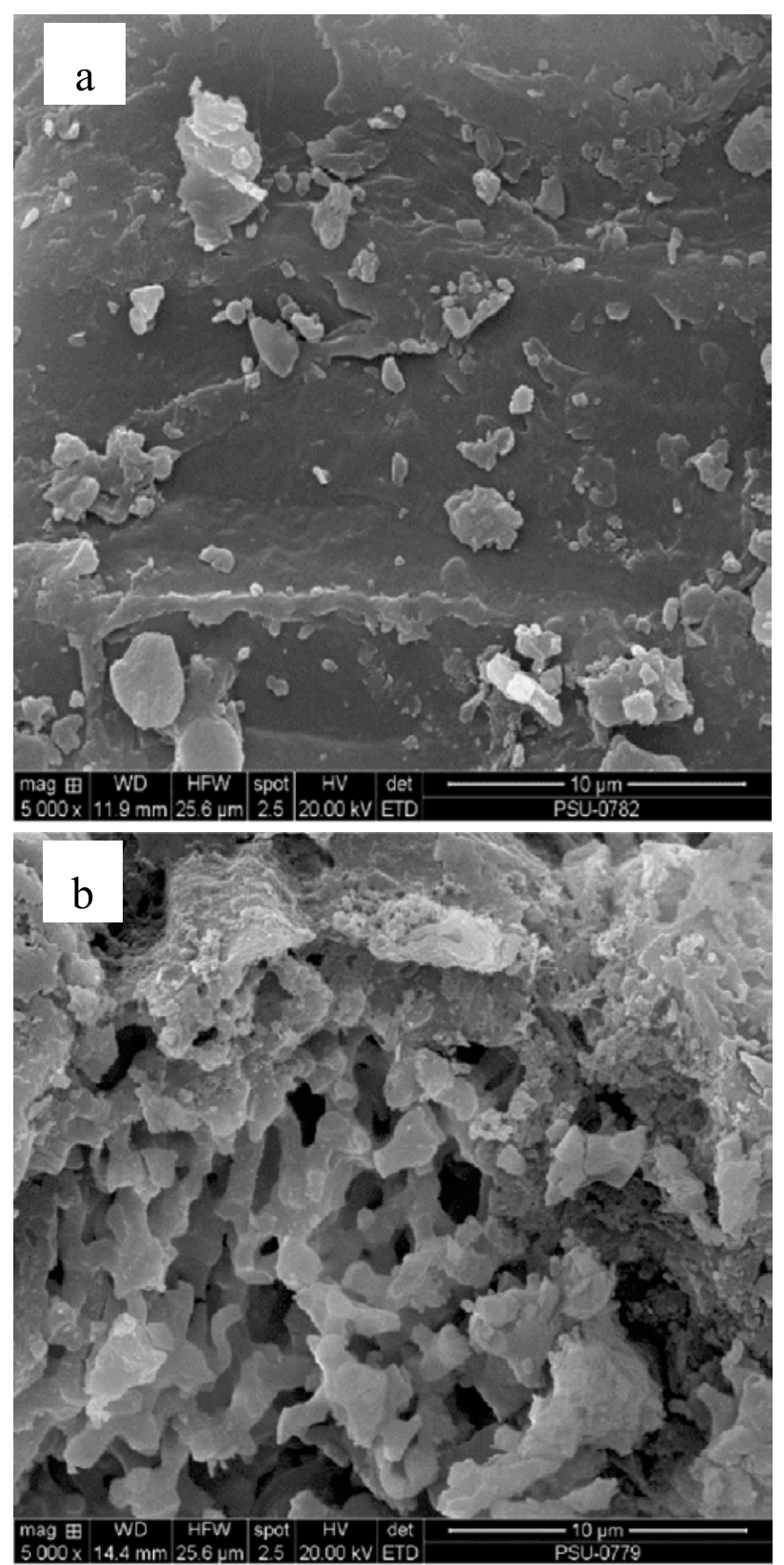

Fig. 1. SEM morphology of MOPF a) and hydrochar b).

produced a similar result to this observation where the microspheres in hydrochar derived from golden shower at $190^{\circ} \mathrm{C}$ for $24 \mathrm{~h}$ were caused by weak decomposition of cellulose and lignin. A high cellulose and lignin fraction in the raw material might prevent pathway pores forming from carbon spheres [30].

The FTIR spectra of hydrochar and MOPF are displayed in Fig. 2 showing the important functional groups. The spectra of the hydrochar and the raw material showed similar profiles, denoting that the MOPF had not been totally decomposed into char during the $\mathrm{HTC} 180^{\circ} \mathrm{C}$ for $8 \mathrm{~h}$. But it is possible to detect a decrease in the intensity at the bands centered at 1600, 1100, and $780 \mathrm{~cm}^{-1}$. The broad band at $3200-3600 \mathrm{~cm}^{-1}$ corresponds to the stretching vibration of O-H groups from the phenol groups of hemicellulose, 


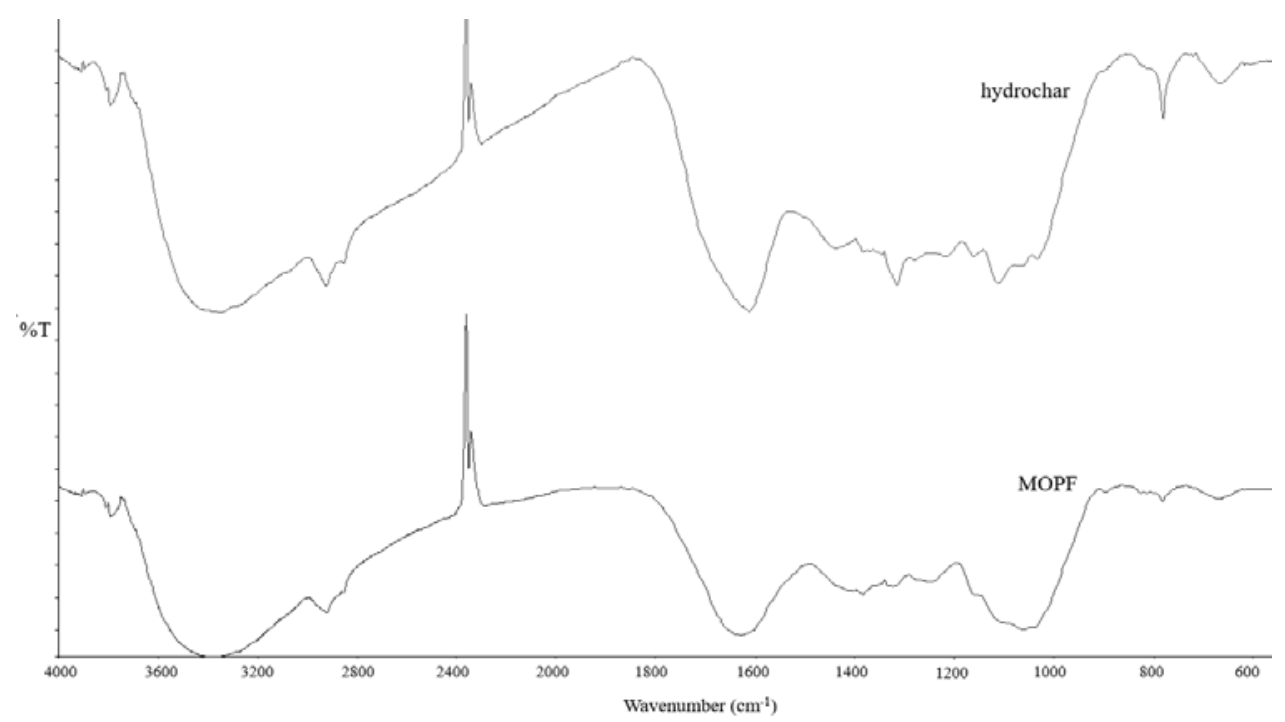

Fig. 2. IR Spectra of MOPF and hydrochar.

cellulose, and lignin and $\mathrm{N}-\mathrm{H}$ stretching vibration [31]. However, the hydroxyl peak in the MOPF was stronger than in the hydrochar due to the organic acid content in the biomass consisting of carboxyls, phenols and/or chemisorbed water $[19,30]$ and due to the removal of the $\mathrm{H}$ and $\mathrm{O}$ from the hydrochar due to the dehydration and decarboxylation processesduring the formation of $\mathrm{H}_{2} \mathrm{O}$ and $\mathrm{CO}_{2}$ as liquid products [26]. C-H stretching in the aliphatic $\mathrm{CH}, \mathrm{CH}_{2}$, and $\mathrm{CH}_{3}$ groups and aromatic $\mathrm{C}=\mathrm{C}$ bending (due to the aromatic characteristic of lignin) are apparent at the bands at $2920 \mathrm{~cm}^{-1}$ and $1620 \mathrm{~cm}^{-1}$, respectively. The band at $1437 \mathrm{~cm}^{-1}$ attributed to $\mathrm{C}-\mathrm{H}$ appeared in the hydrocharperhaps because of incomplete lignin degradation [19]. Conversely, the peak at $1249 \mathrm{~cm}^{-1}$ assigned to $\mathrm{C}-\mathrm{O}$ (alcohols, carboxylic acids, esters, and ethers), did not appear in the hydrochar spectrum because of the decarboxylation reaction during the HTC process. The taper band at $780 \mathrm{~cm}^{-1}$ in the hydrochar indicates deformities due to out-of-plane angular benzene derivatives that were assigned to $=\mathrm{CH}$ bending vibration [26].

Hydrocharspectra before and after adsorption were also compared and investigated and are presented in Fig. 3. A slight change in the spectra after adsorption was observed, indicating that a reaction mechanism had occurred in the adsorption of MB by the hydrochar prepared from MOPF. Firstly, a dissipated peak at $1437 \mathrm{~cm}^{-1}$ after MB sorption onto the hydrocharindicatesan interaction due to cationic exchange between the molecules in the cationic MB dye and the $\mathrm{H}^{+}$from the $\mathrm{C}-\mathrm{H}$ [32]. The peaks from the carboxylic $(-\mathrm{COOH})$ and hydroxylic $(-\mathrm{OH})$ groups reduced and shifted to lower wavelengths after sorption of $\mathrm{MB}$, which also indicates a complex reaction being involved in the cationic MB binding mechanism with the hydrochar. This was also confirmed in previous

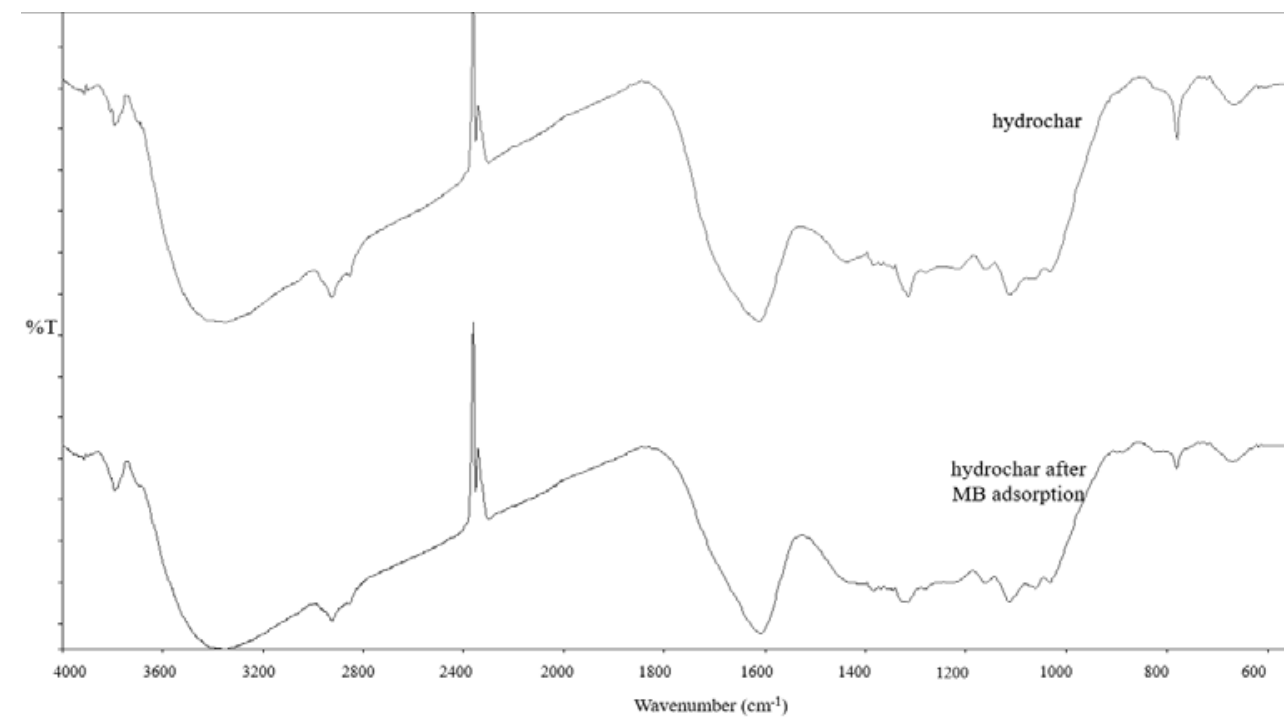

Fig. 3. IR Spectra of hydrochar before and after adsorption. 
research by Islam et al. [18]. In addition, a depleted band at $780 \mathrm{~cm}^{-1}$ after adsorption was observed, possibly due to an interaction between the phi-phi bonding of the benzene derivative and the cationic dye molecules [32].

Previous work by Nakason et al. [24] investigated corncob-derived hydrochar from HTCat $180^{\circ} \mathrm{C}$ for $3 \mathrm{~h}$, and found $-\mathrm{OH}$ groups on both materials. But there was a lower intensity found on the hydrochar than on the raw material, which was attributed to the dehydration reaction during HTC. This result also corresponded to a reduction in oxygen. A decreased amount of hemicellulose was observed in the bands at 1700 and $1730 \mathrm{~cm}^{-1}$, which was attributed to $\mathrm{C}=\mathrm{O}$ stretching. Moreover, cellulose and lignin still remained in the hydrochar, which can be seen from the peak at 2800 to $3000 \mathrm{~cm}^{-1}$ assigned to aliphatic $\mathrm{C}-\mathrm{H}$ stretching and at 1600 to $1515 \mathrm{~cm}^{-1}$ corresponding to aromatic $\mathrm{C}=\mathrm{C}$.

The IR spectra after adsorption was comparable with that before adsorption and in order to investigate the possible adsorption mechanism Islam et al. [18] used rattan biomass-based hydrochar with activation. The spectra after adsorption of MB showed the disappearance of some bands corresponding to active functional groups in the adsorption. and the $\mathrm{O}-\mathrm{H}$ and $\mathrm{C}=\mathrm{O}$ groups attributed to the bands at $3200-3600 \mathrm{~cm}^{-1}$ and $1994 \mathrm{~cm}^{-1}$, respectively were lost after adsorption. This result is similar to the present work in which $\mathrm{C}=\mathrm{O}$ and $\mathrm{O}-\mathrm{H}$ was involved in $\mathrm{MB}$ adsorption, even though the hydrochar was without activation.

\section{Adsorption Study}

The study of the MB adsorption was performed in terms of adsorption efficiency $(\% \mathrm{E})$ against contact time (Fig. 4). The adsorption of the MB solution was conducted in batch mode over the course of 48 $\mathrm{h}$ in order to also study the kinetics. MB solutions with different concentrations $\left(25,50\right.$ and $\left.300 \mathrm{mg} \cdot \mathrm{L}^{-1}\right)$ reached equilibrium at different times. The $\mathrm{MB}$ adsorption efficiency of the hydrochar increased consistent with longer time periods. A rapid increase occurred at $15 \mathrm{~min}, 30 \mathrm{~min}$, and $4 \mathrm{~h}$ for 25,50 and $300 \mathrm{mg} \cdot \mathrm{L}^{-1}$, respectively. Those were assigned to the first step of MB adsorption onto the hydrochar's surface, while the following kinetic steps towards equilibrium were slow, which was related to the inner surfaces of the adsorbent. The rapid increase in the first step of MB adsorption occurs because the MB ions have less affinity with the solvent (water) and have low water solubility [14]. On the other hand, the subsequent slow sorption is probably due to competitive attraction between the MB molecules and the active sites on the hydrochar's surface [18]. After the short initial period of high adsorption of $\mathrm{MB}$ the adsorption rate became steady because only a small amount of adsorbate molecules could be adsorbed by the same amount of active sites on the hydrochar-based adsorbent. This finding is similar to that of Khanday et al. [33], with a zeolite-activated carbon composite from oil palm

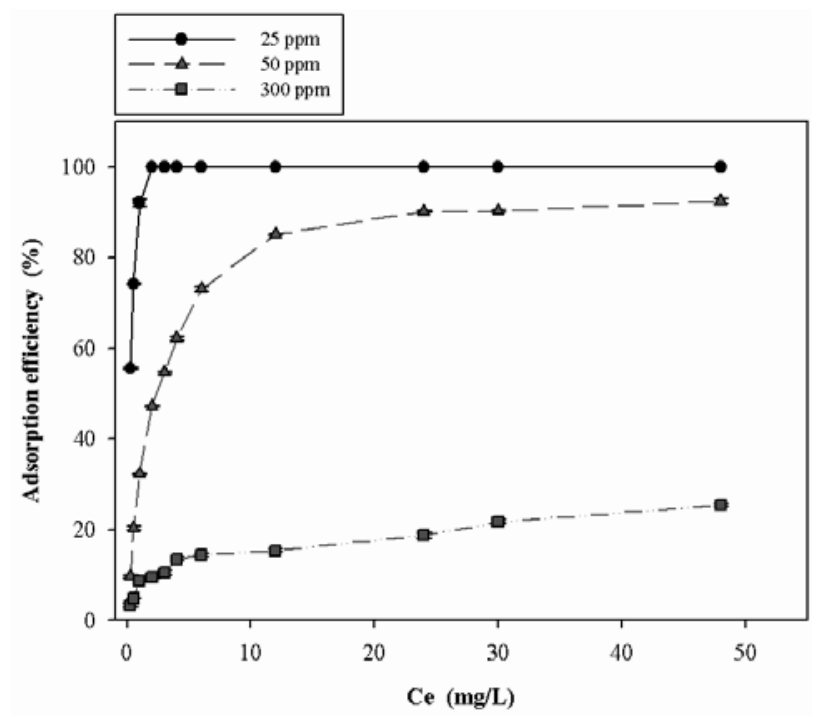

Fig. 4. Adsorption efficiency of hydrochar towards MB 25, 50, and $300 \mathrm{mg} \cdot \mathrm{L}^{-1}$.

ash. The initial MB concentrations reached adsorption equilibrium after $24 \mathrm{~h}$ and this contact time is useful as a standard for adsorption optimization, and hence in the present study all the adsorption experiments were conducted using an equilibrium time of $30 \mathrm{~h}$ to ensure that the MB molecules were completely adsorbed on the active sites of the adsorbent.

Fig. 5 presents the effect of the adsorbent doses on $\mathrm{MB}$ adsorption with the aim of determining MB storage capacity [34] or adsorption efficiency at a specified initial adsorbate concentration $\left(50 \mathrm{mg} \cdot \mathrm{L}^{-1}\right)$. Based on a sorbent dose range of $0.005-0.2 \mathrm{~g}$ in $50 \mathrm{~mL}$, the highest amount of adsorbent produced the best MB adsorption efficiency of the hydrochar. The increase of adsorption efficiency from $7-99 \%$ was consistent with the increase in sorbent doses. This result is probably due to the adsorbent possessing an adequate surface area and active sites. Hence with every increase even by a small amount, the adsorbent offers a much greater surface area and more adsorption sites to adsorb a given number of MB molecules [35]. In this experiment, $0.20 \mathrm{~g}$ of adsorbent produced the highest adsorption efficiency at $99 \%$, since this presented the largest number of surface sites. As the comparative study of MOPF and hydrochar in $\mathrm{MB}$ removal. The removal capacity of hydrochar was $3-5 \%$ higher than MOPF in this study due to the high surface area (Table 1).

\section{Isotherm Study}

Isotherm study was conducted in order to explainthe relationship between the adsorbate (MB) concentration and the solid phase (hydrochar). Isotherm study also allows for determining the extent of the adsorption capacity $\left(Q_{e}\right)$ through predictive calculation of the adsorption isotherm models [33]. The initial MB concentration range of $25-300 \mathrm{mg} \cdot \mathrm{L}^{-1}$ was simulated in 


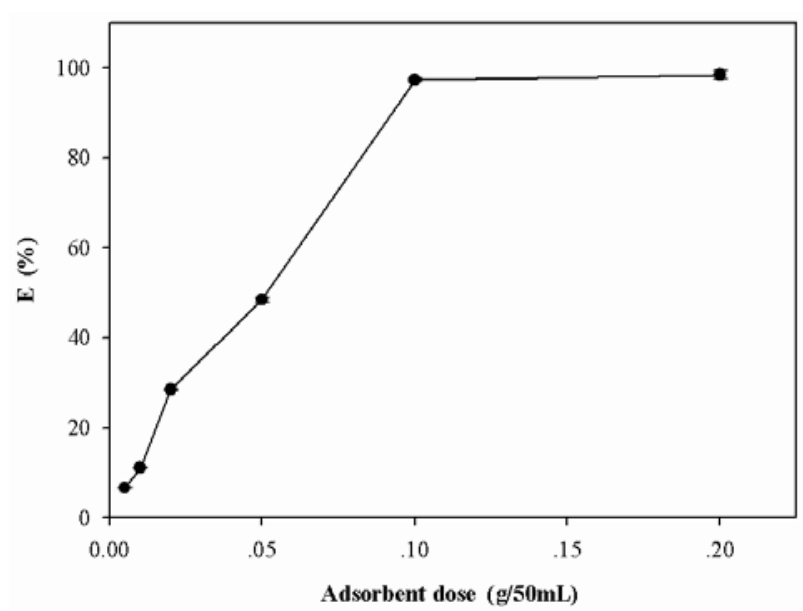

Fig. 5. MB adsorption performance in terms of adsorbent doses effect.

the models to obtain corresponding values for the MB adsorption capacity of the hydrochar. Both Langmuir and Freundlich isotherm models were constructed in this study and are summarized in Table 2.

Langmuir isotherm models describe homogeneous monolayer adsorption on identical surface sites of the adsorbent with a corresponding energy level distribution [36]. The linear form of the Langmuir equation is expressed as Equation (3):

$$
1 / \mathrm{Q}_{\mathrm{e}}=\left(1 / \mathrm{Q}_{\mathrm{m}} \cdot \mathrm{K}_{\mathrm{L}}\right)\left(1 / \mathrm{C}_{\mathrm{e}}\right)+\left(1 / \mathrm{Q}_{\mathrm{m}}\right)
$$

...where $\mathrm{C}_{\mathrm{e}}\left(\mathrm{mg} \cdot \mathrm{L}^{-1}\right)$ and $\mathrm{Q}_{\mathrm{e}}\left(\mathrm{mg} \cdot \mathrm{g}^{-1}\right)$ is the concentration of $\mathrm{MB}$ solution after adsorption at equilibrium time and the adsorbed concentration of MB per adsorbent weight unit, respectively. $\mathrm{K}_{\mathrm{I}}$ is the Langmuir constant related to the free energy of adsorption $\left(\mathrm{L} \cdot \mathrm{mg}^{-1}\right) \cdot \mathrm{Q}_{\mathrm{m}}$ is the maximum adsorption capacity obtained from the Langmuir model calculation. Whether the data is a good fit to the Langmuir model or not can be seen from the $R_{L}$ (separation factor of the Langmuir isotherm model) value. This isotherm type can be linear $\left(R_{L}=1\right)$, favorable $\left(0<R_{L}>1\right)$, unfavorable $\left(R_{L}>1\right)$ or irreversible $\left(R_{L}=0\right)$ [36]. The equation of $R_{L}$ is as follows (4):

Table 2. Parameters of isotherm models for MB adsorption on hydrochar at $30^{\circ} \mathrm{C}$.

\begin{tabular}{|c|c|c|}
\hline Isotherms & Parameters & Values \\
\hline \multirow{4}{*}{ Langmuir } & $\mathrm{Q}_{\mathrm{L}}\left(\mathrm{mg} \cdot \mathrm{g}^{-1}\right)$ & 42.92 \\
\cline { 2 - 3 } & $\mathrm{K}_{\mathrm{L}}\left(\mathrm{L} \cdot \mathrm{mg}^{-1}\right)$ & 0.28 \\
\cline { 2 - 3 } & $\mathrm{R}^{2}$ & 0.9766 \\
\hline \multirow{3}{*}{ Freundlich } & $\mathrm{K}_{\mathrm{F}}$ & 14.59 \\
\cline { 2 - 3 } & $\mathrm{n}$ & 4.29 \\
\cline { 2 - 3 } & $\mathrm{R}^{2}$ & 0.8535 \\
\hline
\end{tabular}

$$
\mathrm{R}_{\mathrm{L}}=1 /\left(1+\mathrm{K}_{\mathrm{L}} \mathrm{C}_{0}\right)
$$

The second isotherm model used was a Freundlichmodel, which assumes that adsorption occurs due to the adsorbed molecules interacting with a heterogeneous multilayer surface. The binding strength decreases after the binding sites are occupied because of occupied-site degree enhancement [37]. The model is expressed in the following Equation (5):

$$
\log \mathrm{Q}_{\mathrm{e}}=(1 / \mathrm{n}) \log \mathrm{C}_{\mathrm{e}}+\log \mathrm{K}_{\mathrm{F}}
$$

...where $\mathrm{K}_{\mathrm{F}}$ and $\mathrm{n}$ are the Freundlich constant and the heterogeneity factor, respectively.

In the present study, the adsorption of MB is a better fit to the Langmuir isotherm model because the R2 was closest to 1 (0.9766). This isotherm model is favorable, with RL equal to $0.0667,0.0345,0.0233,0.0175,0.0141$, and 0.0101 for $\mathrm{MB}$ initial concentrations of 50, 100, $150,200,250$, and $300 \mathrm{mg} \cdot \mathrm{L}^{-1}$, respectively, and a

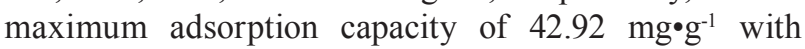
$0.2 \mathrm{~g}$ of adsorbent. This indicates that monolayer adsorption occurred during $\mathrm{MB}$ removal by the hydrochar prepared from MOPF. In addition, the cationic $\mathrm{MB}$ dye occupied specific homogeneous sites on the hydrochar's surface, which possesses hydroxyl and carboxyl functional groups, a finding which is similar to [11].

\section{Kinetic Study}

Kinetic study is important for establishing whether a small-scale reaction can be scaled up to industry level efficiency and economic viability [30]. Kinetic models are also applied to determine the rate-controlling step and to study the sorption mechanism of the MB onto the hydrochar-based adsorbent. Pseudo first-order (PFO) and pseudo second-order (PSO) kinetic models were plotted to investigate the adsorption rate and the mechanism of MB adsorption by the hydrochar. Equations (6) and (7) used are as follows [17]:

PFO

$$
\log \left(\mathrm{Q}_{\mathrm{e}}-\mathrm{Q}_{\mathrm{t}}\right)=\log \mathrm{Q}_{\mathrm{e}}-\left(\mathrm{k}_{1} \mathrm{t}\right) / 2.303
$$

PSO

$$
\mathrm{t} / \mathrm{Q}_{\mathrm{t}}=1 /\left(\mathrm{k}_{2} \mathrm{Q}_{\mathrm{e}}^{2}\right)+\mathrm{t} / \mathrm{Q}_{\mathrm{e}}
$$

...where $\mathrm{Q}_{\mathrm{e}}$ and $\mathrm{Q}_{\mathrm{t}}$ are the amount of $\mathrm{MB}$ adsorbed at time $\mathrm{t}$ and at equilibrium time in units of $\mathrm{mg} \cdot \mathrm{g}^{-1}$, respectively, and $\mathrm{k}_{1}\left(1 \cdot \mathrm{h}^{-1}\right)$ and $\mathrm{k}_{2}\left(\mathrm{~g}(\mathrm{mg} \cdot \mathrm{h})^{-1}\right)$ are the PFO and PSO rate constants, respectively.

Based on the results shown in Table 3, the adsorption of MB onto the hydrochar followed a PSO model because the $\mathrm{R}^{2}$ for all initial concentrations of $\mathrm{MB}$ were close to linear $\left(\mathrm{R}^{2}>0.980\right)$, indicating that the ratecontrolling step for $\mathrm{MB}$ adsorption onto the hydrochar was chemisorption. The values of the $\mathrm{k}_{1}$ and $\mathrm{k}_{2}$ rate constants were dependent on the initial concentration 
Table 3. Kinetic study of MB adsorption on hydrochar.

\begin{tabular}{|c|c|c|c|c|c|c|c|c|c|}
\hline \multirow{2}{*}{$\mathrm{C}_{0} \mathrm{MB}\left(\mathrm{mg} \cdot \mathrm{L}^{-1}\right)$} & \multirow{3}{*}{$\begin{array}{c}\mathrm{Q}_{\mathrm{e}, \text { exp }} \\
\left(\mathrm{mg} \cdot \mathrm{g}^{-1}\right)\end{array}$} & $\begin{array}{c}\mathrm{Q}_{\mathrm{e}, \mathrm{cal}} \\
\left(\mathrm{mg} \cdot \mathrm{g}^{-1}\right)\end{array}$ & $\begin{array}{c}\mathrm{k}_{1} \\
\left(1 \cdot \mathrm{h}^{-1}\right)\end{array}$ & $\mathrm{R}^{2}$ & RMSE & $\begin{array}{c}\mathrm{Q}_{\mathrm{e}, \mathrm{cal}} \\
\left(\mathrm{mg} \cdot \mathrm{g}^{-1}\right)\end{array}$ & $\begin{array}{c}\mathrm{k}_{2} \\
\left(\mathrm{~g}(\mathrm{mg} \cdot \mathrm{h})^{-1}\right)\end{array}$ & $\mathrm{R}^{2}$ & $\mathrm{RMSE}$ \\
\hline 25 & 27.00 & 24.72 & 2.427 & 0.994 & 2.28 & 27.10 & 0.317 & 1 & 0.10 \\
\hline 50 & 47.52 & 32.98 & 0.104 & 0.905 & 14.54 & 49.75 & 0.009 & 0.997 & 2.23 \\
\hline 300 & 71.54 & 51.25 & 0.080 & 0.903 & 20.29 & 72.99 & 0.005 & 0.986 & 1.45 \\
\hline
\end{tabular}

Table 4. Comparative study of $\mathrm{MB}$ adsorption on adsorbents from different biomass sources.

\begin{tabular}{|c|c|c|c|}
\hline Adsorbent & $\begin{array}{c}\text { Temperature } \\
\left({ }^{\circ} \mathrm{C}\right)\end{array}$ & $\begin{array}{c}\text { Qe } \\
\left(\mathrm{mg} \cdot \mathrm{g}^{-1}\right)\end{array}$ & References \\
\hline $\begin{array}{c}\text { Sewage sludge + tea } \\
\text { waste biochar }\end{array}$ & 45 & 19.38 & {$[38]$} \\
\hline Oak wood biochar & 50 & 97.55 & {$[36]$} \\
\hline $\begin{array}{c}\text { Oil palm ash activated } \\
\text { carbon-zeolite }\end{array}$ & 30 & 143.47 & {$[33]$} \\
\hline $\begin{array}{c}\text { Rattan derived } \\
\text { activated carbon }\end{array}$ & 30 & 359 & {$[11]$} \\
\hline \begin{tabular}{c} 
Kaolin (Algeria) \\
\hline $\begin{array}{c}\text { MOPF-based } \\
\text { hydrochar }\end{array}$
\end{tabular} & 30 & 42.92 & This work \\
\hline
\end{tabular}

since both models gave different results with changes in the initial concentration. However, the change in $\mathrm{k}_{2}$ was greater than that in $\mathrm{k}_{1}$. A similar adsorption mechanism has also been investigated in previous research [35, 38-39].

Table 4 presents a comparison of the outcome of $\mathrm{MB}$ removal in this study using MOPF-based hydrochar with that achieved with other biomass sources. Although the adsorption capacity of MB by hydrochar is lower than that of several other adsorbents, MOPF-derived hydrochar was still better than some natural adsorbent sources such as natural zeolite, which suggests that hydrochar represents a low-cost efficient adsorbent for dye removal. Since MOPF is otherwise of no use, MOPF could be combined with other parts of the oil palm tree and used as adsorbent in order to be utilized as a valueadded material.

\section{Conclusions}

Hydrochar was successfully derived from MOPF through HTC. The physicochemical characteristics of the hydrochar were investigated and good properties were found in terms of surface area, actives sites of functional groups, texture and morphology. In addition, the adsorption parameters of MB removal were observed and produced successful adsorption with a maximum Langmuir monolayer adsorption capacity value of $42.92 \mathrm{mg} \cdot \mathrm{g}^{-1}$ at $30^{\circ} \mathrm{C}$. The mechanism of MB adsorption was found to be an attractive phenomenon instead of being due to electrostatic force, and the rate-limiting step followed a PSO model. These results suggest that hydrochar derived from MPFO, which is a renewable biomass source, could provide the basis of a material efficient for removing dyes in wastewater treatment and as an aid to zero-waste management.

\section{Acknowledgements}

This research was fully supported by the Graduate School, Prince of Songkla University, Thailand. The first author acknowledges the award of a TEH-AC (Thailand's Education Hub for Southern Region of ASEAN Countries) scholarship in support of a master's degree under contract No. THE-AC 010/2016.

The authors would like thankfully acknowledge research grants from the Faculty of Environmental Management, Prince of Songkla University (No. ENV6103)

\section{Conflict of Interest}

The authors declare no conflict of interest.

\section{References}

1. PETCHSEECHOUNG W. Thailand Industry Outlook 2016-18: Oil Palm Industry. Krungsri Research, Thailand. 2016.

2. AWALLUDIN M.F., SULAIMAN O., HASHIM R., NADHARI W.N.A.W. An overview of the oil palm industry in Malaysia and its waste utilization through thermochemical conversion, specifically via liquefaction. Renewable and Sustainable Energy Reviews, 50, 1469, 2015.

3. ADAM H., COLLIN M., RICHAUD F., BEULÉ T., CROS D., OMORÉ A., NODICHAO L., NOUY B., TREGEAR J.W. Environmental regulation of sex determination in oil palm: current knowledge and insights from other species. Annals of Botany, 108, 1529, 2011.

4. KHOSRAVIHAFTKHANY S., MORAD N., TENG T.T., ABDULLAH A.Z., NORLI I. Biosorption of $\mathrm{Pb}(\mathrm{II})$ and $\mathrm{Fe}(\mathrm{III})$ from aqueous solutions using oil palm biomasses as adsorbents. Water, Air, \& Soil Pollution, 224 (3), 1455, 2013.

5. KARRI R.R., SAHU J.N. Modeling and optimization by particle swarm embedded neural network for adsorption 
of zinc (II) by palm kernel shell based activated carbon from aqueous environment. Journal of Environmental Management, 206, 178, 2018.

6. LEE X.J., LEE L.Y., GAN S., THANGALAZHYGOPAKUMAR S., NG H.K. Biochar potential evaluation of palm oil wastes through slow pyrolysis: Thermochemical characterization and pyrolytic kinetic studies. Bioresource Technology, 236, 155, 2017.

7. GARCÍA J.R., SEDRAN U., ZAINI M.A.A., ZAKARIA Z.A. Preparation, characterization, and dye removal study of activated carbon prepared from palm kernel shell. Environmental Science and Pollution Research. 25 (6), 5076, 2018.

8. HUSSIN M.H.,POHAN N.A., GARBA Z.N., KASSIM M.J., RAHIM A.A., BROSSE N., YEMLOUL M., FAZITA M.R.N., HAAFIZ M.K.M. Physicochemical of microcrystalline cellulose from oil palm fronds as potential methylene blue adsorbents. International Journal of Biological Macromolecules, 92, 11, 2016.

9. HAN L., SUN H., RO K.S., SUN K., LIBRA J.A., XING B. Removal of antimony (III) and cadmium (II) from aqueous solution using animal manure-derived hydrochars and pyrochars. Bioresource Technology, 234, 77, 2017.

10. ZHANG X., ZHANG L., LI A. Eucalyptus sawdust derived biochar generated by combining thehydrothermal carbonization and low concentration $\mathrm{KOH}$ modification for hexavalent chromium removal. Journal of Environmental Management, 206, 989, 2018.

11. ISLAM M.A., AHMED M.J., KHANDAY W.A., ASIF M., HAMEED B.H. Mesoporous activated carbon prepared from $\mathrm{NaOH}$ activation of rattan (Lacosperma secundiflorum) hydrochar for methylene blue removal. Ecotoxicology and Environmental Safety, 138, 279, 2017.

12. RAKIĆ V., RAJIĆ N., DAKOVIĆ A., AUROUX A. The adsorption of salicylic acid, acetylsalicylic acid and atenolol from aqueous solutions onto natural zeolites and clays: Clinoptilolite, bentonite and kaolin. Microporous and Mesoporous Materials, 166, 185, 2013.

13. KAMBO H.S., DUTTA A. A comparative review of biochar and hydrochar in terms of production, physicochemical properties and applications. Renewable \& Sustainable Energy Reviews, 45, 359, 2015.

14. GUOH., BI C., ZENG C., MA W., YAN L., LI K., WEI K.Camellia oleifera seed shell carbon as an efficient renewable bio-adsorbent for the adsorption removal of hexavalent chromium and methylene blue from aqueous solution. Journal of Molecular Liquids, 249, 629, 2018.

15. FANG J., GAO B., CHEN J., ZIMMERMAN A.R. Hydrochars derived from plant biomass under various conditions: Characterization and potential applications and impacts. Chemical Engineering Journal, 267, 253, 2015.

16. FUNKE A., ZIEGLER F. Hydrothermal Carbonization of Biomass: A Summary and Discussion of Chemical Mechanisms for Process Engineering. Biofuels, Bioproducts \& Biorefining, 4, 160, 2010.

17. ESSANDOH M., KUNWAR B., PITTMAN C.U., MOHAN D., MLSNA T. Sorptive removal of salicylic acid and ibuprofen from aqueous solutions using pine wood fast pyrolysis biochar. Chemical Engineering Journal, 265, 219, 2015.

18. ISLAM M.A., AHMED M.J., KHANDAY W.A., ASIF M., HAMEED B.H. Mesoporous activated coconut shell-derived hydrochar prepared via hydrothermal carbonization- $\mathrm{NaOH}$ activation for methylene blue adsorption. Journal of Environmental Management, 203, 237, 2017.
19. ZHOU N.,CHEN H., FENG Q., YAO D., CHEN H., WANG H., ZHOU Z., LI H., TIAN Y., LU X. Effect of phosphoric acid on the surface properties and $\mathrm{Pb}(\mathrm{II})$ adsorption mechanisms of hydrochars prepared from fresh banana peels. Journal of Cleaner Production, 165, 221, 2017.

20. TRAN H.N., CHAO H.-P., YOU S.-J. Activated carbons from golden shower upon different chemical activation methods: Synthesis and characterizations. Adsorption Science \& Technology, 36 (1-2), 95, 2018.

21. SIMSIR H., ELTUGRAL N., KARAGOZ S. Hydrothermal carbonization for the preparation of hydrochars from glucose, cellulose, chitin, chitosan and wood chips via low-temperature and their characterization. Bioresource Technology, 246, 82, 2017.

22. NIZAMUDDIN S., MUBARAK N.M., TIRIPATHI M., JAYAKUMAR N.S., SAHU J.N., GANESAN P. Chemical, dielectric and structural characterization of optimized hydrochar produced from hydrothermal carbonization of palm shell. Fuel, 163, 88, 2016.

23. CHEN X., MA X., PENG X., LIN Y., YAO Z. Conversion of sweet potato waste to solid fuel via hydrothermal carbonization. Bioresource Technology, 249, 900, 2018.

24. NAKASON K., PANYAPINYOPOL B., KANOKKANTAPONG V., VIRIYA-EMPIKUL N., KRAITHONG W., PAVASANT P. Characteristics of hydrochar and liquid fraction from hydrothermal carbonization of cassava rhizome. Journal of the Energy Institute, 91 (2), 184, 2018.

25. HUQ.,YANG H., YAO D., ZHU D., WANG X., SHAO J., CHEN H. The densification of bio-char: Effect of pyrolysis temperature on the qualities of pellets. Bioresource Technology, 200, 521, 2016.

26. SALIMI M., BALOU S., KOHANSAL K., BABAEI K., TAVASOLI A., ANDACHE M. Optimizing the preparation of meso- and microporous canola stalk-derived hydrothermal carbon via response surface methodology for methylene blue removal. Energy\&Fuels, 31(11), 12327, 2017.

27. RONIX A., PEZOTI O., SOUZA L.S, SOUZA I.P.A.F., BEDIN K.C., SOUZA P.S.C., SILVA T.L., MELO S.A.R., CAZETTA A.L., ALMEIDA V.C. Hydrothermal carbonization of coffee husk: Optimization of experimental parameters and adsorption of methylene blue dye. Journal of Environmental Chemical Engineering, 5 (5), 4841, 2017.

28. ZHU X., LIU Y.,QIAN F., ZHOU C., ZHANG S., CHEN J. Role of Hydrochar Properties on the Porosity of Hydrochar-based Porous Carbon for Their Sustainable Application. ACS Sustainable Chemistry \& Engineering, 3 (5), 833, 2015.

29. WANGF. A novel magnetic activated carbon produced via hydrochloric acid pickling water activation for methylene blue removal. Journal of Porous Materials, 25 (2), 611, 2018.

30. TRAN H.N., YOU S.-J., CHAO H.-P. Fast and efficient adsorption of methylene green 5 on activated carbon prepared from new chemical activation method. Journal of Environmental Management, 188, 322, 2017.

31. SHI Y., ZHANG T., REN H., KRUSE A., CUI R.Polyethylene imine modified hydrochar adsorption for chromium (VI) and nickel (II) removal from aqueous solution. Bioresource Technology, 247, 370, 2018.

32. ISLAM M.A., TAN I.A.W., BENHOURIA A., ASIF M., HAMEED B.H. Mesoporous and adsorptive properties of palm date seed activated carbon prepared via sequential 
hydrothermal carbonization and sodium hydroxide activation. Chemical Engineering Journal, 270, 187, 2015.

33. KHANDAY W.A., MARRAKCHI F., ASIF M., HAMEED B.H. Mesoporous zeolite-activated carbon composite from oil palm ash as an effective adsorbent for methylene blue. Journal of the Taiwan Institute of Chemical Engineers, 70, 32, 2017.

34. CHENX., CHEN G., CHEN L., CHEN Y., LEHMANN J., MCBRIDE M.B., HAY A.G. Adsorption of copper and zinc by biochars produced from pyrolysis of hardwood and corn straw in aqueous solution. Bioresource Technology, 102 (19), 8877, 2011.

35. MOUNIL.,BELKHIRI L., BOLLINGER J.C., BOUZAZA A., ASSADI A., TIRRI A., DAHMOUNE F., MADANI K., REMINI H. Removal of Methylene Blue from aqueous solutions by adsorption on Kaolin: Kinetic and equilibrium studies. Applied Clay Science, 153, 38, 2018.

36. ZHAOL.,YANG F., JIANG Q., ZHU M., JIANG Z., TANG Y., ZHANG Y.Characterization of modified biochars prepared at low pyrolysis temperature as an efficient adsorbent for atrazine removal. Environmental Science and Pollution Research, 25 (2), 1405, 2018.

37. RUTHIRAAN M., ABDULLAH E.C., MUBARAK N.M., NORAINI M.N.A promising route of magnetic based materials for removal of cadmium and methylene blue from waste water. Journal of Environmental Chemical Engineering. 5 (2), 1447, 2017.

38. FANS.,TANG J., WANG Y., LI H., ZHANG H., TANG J., WANG Z., LI X. Biochar prepared from co-pyrolysis of municipal sewage sludge and tea waste for the adsorption of methylene blue from aqueous solutions: Kinetics, isotherm, thermodynamic and mechanism. Journal of Molecular Liquids, 220, 432, 2016.

39. DANESHVAR E., VAZIRZADEH A., NIAZI A., KOUSHA M., NAUSHAD M., BHATNAGAR A.Desorption of Methylene blue dye from brown macroalga: Effects of operating parameters, isotherm study and kinetic modeling. Journal of Cleaner Production, 152, 443, 2017 